\title{
Treatment of Keloids Using Plasma Skin Regeneration Combined with Radiation Therapy Under the Evaluation of Patient and Observer Scar Assessment Scale
}

\author{
Wenyun Ting $\mathbb{( D}^{1, *}$ \\ Yuming Chong $\mathbb{D}^{1,2, *}$ \\ Jing $\mathrm{Xu}^{2}$ \\ Jiuzuo Huang' \\ Nanze $\mathrm{Yu}^{\prime}$ \\ Zhifei Liu'
}

'Department of Plastic and Aesthetic Surgery, Peking Union Medical College Hospital, Chinese Academy of Medical Sciences \& Peking Union Medical College, Beijing, People's Republic of China;

${ }^{2}$ Chinese Academy of Medical Sciences \& Peking Union Medical College, Beijing,

People's Republic of China

*These authors contributed equally to this work
Correspondence: Zhifei Liu Department of Plastic and Aesthetic Surgery, Peking Union Medical College Hospital, Chinese Academy of Medical Sciences \& Peking Union Medical College, Beijing, People's Republic of China

Email liuzfpumch@I63.com
Purpose: Keloids are caused by uncontrolled excessive proliferation of fibrous tissue. Multiple treatment strategies including steroid injection, surgical excision, laser therapy and radiation therapy have been reported. Few studies have evaluated the performance of plasma skin regeneration (PSR) in the treatment of keloid. This study aimed to evaluate the effectiveness of PSR combined with radiation therapy for keloids on different body parts.

Patients and Methods: A total of 71 patients with 98 keloids were enrolled in this study. Keloids $<4 \mathrm{~mm}$ thick underwent single-dose PSR, while keloids $\geq 4 \mathrm{~mm}$ thick were administered compound betamethasone injection beforehand. Radiation therapy was administered after 24 hours and again 7 days later after PSR. The outcome was evaluated using the patient and observer scar assessment scale at 12 months post-treatment.

Results: Patient-reported average scores for all keloids significantly decreased from 35.05 \pm 9.94 to $21.84 \pm 7.04(\mathrm{p}<0.05)$. Keloids on face and neck, chest, and back responded better than those on shoulders and limbs. The recurrence rate was observed to be $15.3 \%$ (15 out of 98). Adverse effects were mild.

Conclusion: PSR combined with radiation therapy is an effective and safe strategy to treat keloids. Location could be a factor that affects curative effects.

Keywords: keloid, plasma skin regeneration, radiation therapy, POSAS, recurrence rate

\section{Introduction}

Keloids, a type of histologically localized dermal inflammation, are the result of an aberrant healing process featuring abnormal proliferation of fibrous tissue and chronic inflammation after skin injuries reach the reticular dermis. ${ }^{1}$ Due to the excessive amounts of collagen and glycoprotein accumulating in the dermis, keloids progress and enlarge by growing beyond the boundaries of the original wounds, which distinguishes them from hypertrophic scars. The affected skin usually stiffens and gets pruritic, with various color ranges from pink to dark brown.

The current mainstays of treating hypertrophic scars and keloids remain nonstandard with multiple modalities involved, including surgical excision, intralesional steroids, silicone gel, pressure therapy and laser therapy. Surgical excision alone has been proved to result in high recurrence rate because of post-traumatic collagen synthesis stimulation, while subtotal excision with lateral undermining might possibly improve outcome. ${ }^{2}$ In recent years, several studies reported low 
recurrence rate by following surgical excision with other modalities, usually radiation therapy or intralesional steroids injection. ${ }^{3,4}$ Silicone gel, often used as adjuvant treatment after surgery or laser, has also been reported by some studies to be effective in reducing recurrence rate. ${ }^{5}$ Laser therapy includes a series of treatment modalities including neodymium-doped yttrium aluminium garnet (Nd:YAG) laser, carbon dioxide laser and diode laser. ${ }^{6-8}$ Though laser treatment alone had less effectiveness on keloid than hypertrophic scar with high recurrence rate, a combination of laser and other single-application treatments such as silicone gel, and intralesional steroid injections were proven to be an effective and safe therapeutic approach. $^{8}$

In recent years, a novel device, plasma skin regeneration system (PSR) is applied to treat mesh skin-grafted scars and traumatic scars. ${ }^{9}$ Unlike laser therapy which directly applies radio frequency to skin, PSR uses radio frequency to convert nitrogen to plasma, a high-energy state of matter that is emitted at 5-15 millisecond pulses to deliver $1-4 \mathrm{~J}$ of energy. ${ }^{9}$ Plasma then conveys energy to the wounded skin and causes a thermal effect that gasifies proliferative fibrous tissue in the dermis. The effect on skin rejuvenation depends on the amount of plasma energy delivered. Thus, it enables operators to adopt various energy levels and different number of treatments to different wound types and locations.

In this study, the authors innovatively removed keloids with PSR. Given that single treatment may result in high recurrence rate, the authors administrated adjuvant radiotherapy. Radiation therapy has been illustrated to be effective in the control of keloid recurrence by inducing keloid fibroblast apoptosis and destroying collagen structure. ${ }^{2,10}$ The aim of this study is to evaluate the effectiveness and safety of PSR combined with radiation therapy in the treatment of keloids on different body parts.

\section{Patients and Methods Inclusion Criteria}

This study was conducted in accordance with the Declaration of Helsinki. Ethical approval was obtained from the ethics committee of Peking Union Medical College Hospital. Patient data confidentiality was maintained in accordance with the regulations. Written informed consent was waived in light of the retrospective nature of this study. A total of 71 consecutive patients (aged 15-69) with 98 dermal lesions clinically diagnosed as keloids were enrolled in this uncontrolled prospective study, with stipulated selection criteria. The skin types of enrolled patients were type III or IV. The over-extensive growth pattern unconfined to the original wound edges was required as a clinical distinction of keloids from hypertrophic scars.

Patients were excluded from this study if they had previously undergone at least one of the following treatments within the last six months: surgical excision, freeflap grafting, carbon dioxide resurfacing, triamcinolone intralesional injection, silicone gel sheeting, and pressure therapy. Pregnant and lactating patients and those with systemic comorbidities including cardiovascular diseases, diabetes mellitus, and chronic renal failure were also excluded to avoid unnecessary potential risks.

\section{Procedure: PSR Combined with Radiation Therapy}

A clinical evaluation process was developed primarily based on the number, thickness, and texture of the lesions (Figure 1). Each patient admitted for the treatment of keloids underwent this evaluation process. PSR was mainly applied for progressive keloids with multiple lesions. Ideal lesions were no thicker than $4 \mathrm{~mm}$. Patients whose keloids were thicker than $10 \mathrm{~mm}$ were recommended not to receive this treatment, because thick lesions needed high level of energy and too much energy would cause severe side effects. For lesions 4 to $10 \mathrm{~mm}$ thick or those much stiffer than usual, we administered intralesional injections of betamethasone (Diprospan $^{\circledR}$ ) to soften the lesions before PSR.

Plasma was administrated to qualified keloid lesions right after subdermal injection of $0.5 \%$ lidocaine $(5-40 \mathrm{~mL}$, depending on the size of lesion), which spared patients from pain when receiving PSR treatment. Doctors resurfaced the lesions using PSR, making them as flat as the surrounding skin. The patients were asked to cover the lesion with topical antibacterial spray to prevent potential topical infection. External beam irradiation was administered with a total dose of 18 Gy in two fractions, one week apart. Specifically, the first radiation therapy was performed within 24 hours after treatment, and the second was performed 1 week later. The minimum follow-up period was 12 months.

\section{Evaluation of Treatment Outcomes}

Digital photographs were taken to record the morphological characteristics of the keloids before treatment, immediately after treatment and at the end of follow-up. The patient and observer scar assessment scale (POSAS) was used to 


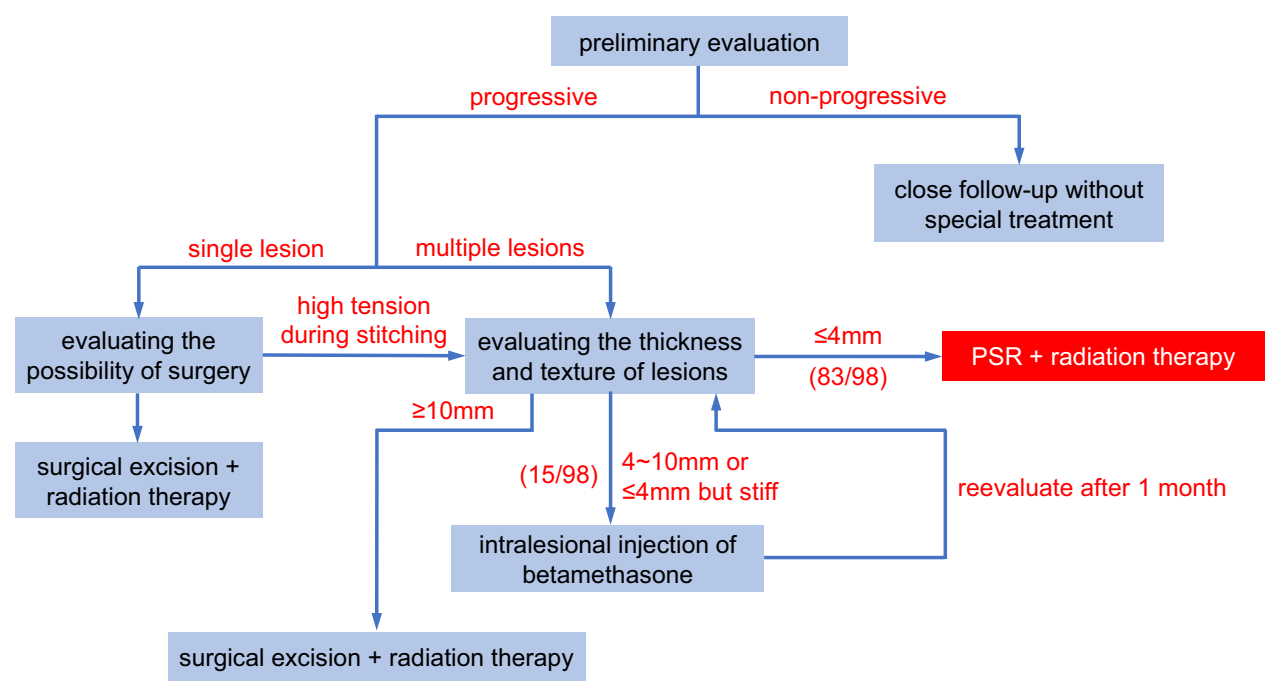

Figure I Clinical evaluation and treatment process for keloids.

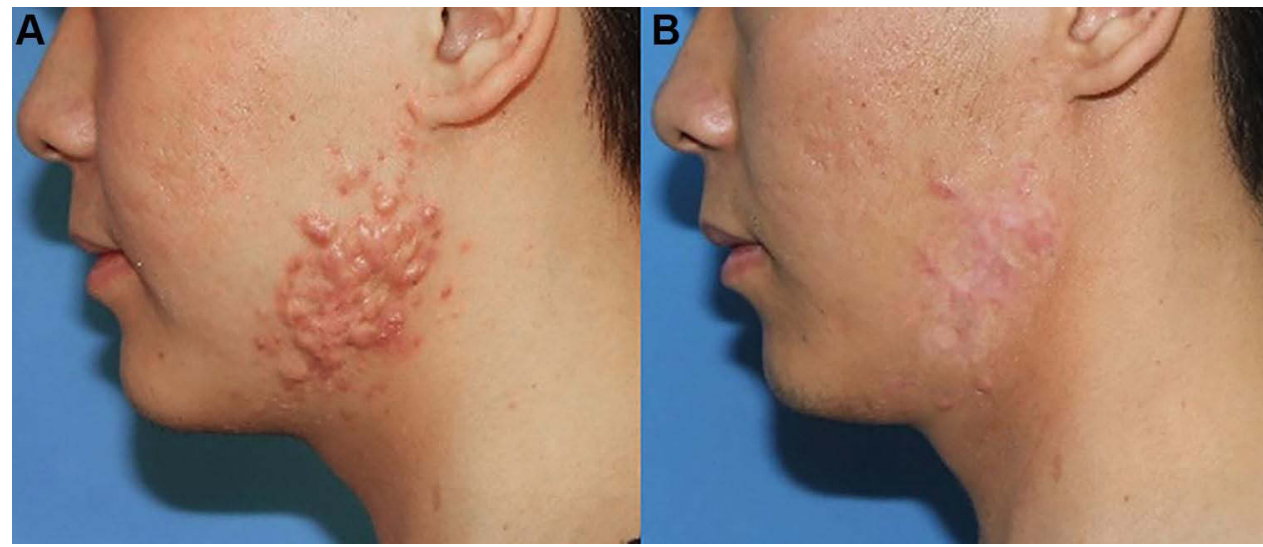

Figure 2 A patient with multiple lesions of keloids on his face prior to treatment (A) and I year after PSR treatment with 2 radiation therapy thereafter (B). No recurrence was found.

evaluate the effect of PSR. ${ }^{11}$ Both patients and observers were asked to fill in the numeric scale before treatment and 12 months posttreatment. To avoid bias, the POSAS observer study was performed independently by an experienced plastic surgeon who was not involved in the treatment.

Means and standard deviations were calculated for each variable. The Student's $t$-test was performed using SPSS 23.0 (IBM, New York, USA) to analyze and summarize all the original data. $\mathrm{P}$ values of $<0.05$ were considered statistically significant.

\section{Results}

\section{Patient Demographics and Lesion Characteristics}

A total of 71 patients (32 males and 39 females) were enrolled in our study. The demographics are summarized in Table 1. Twenty-nine patients were self-reported to have clear incentive such as acne, trauma, and surgical incision. Moreover, 33 patients reported familial inheritance. The 98 lesions were distributed as follows: 23 lesions $(23.5 \%)$ on face and neck, $26(26.5 \%)$ on chest, $16(16.3 \%)$ on shoulders, $16(16.3 \%)$ on the back and $17(17.3 \%)$ on limbs. The average lesion size was $5.03 \pm 0.72 \mathrm{~cm}$. The average re-epithelization duration was $33.78 \pm 10.46$ days.

\section{Results of Patient and Observer Scar Assessment Scale (POSAS) Scoring} According to the patients (Table 2), POSAS scoring showed a significant improvement in the 98 keloids, with the mean score decreasing from $35.05 \pm 9.94$ before treatment to $21.84 \pm 7.04$ ( $\mathrm{p}$ value $<0.05$ ). The mean score of keloids on the face and neck dropped significantly from 


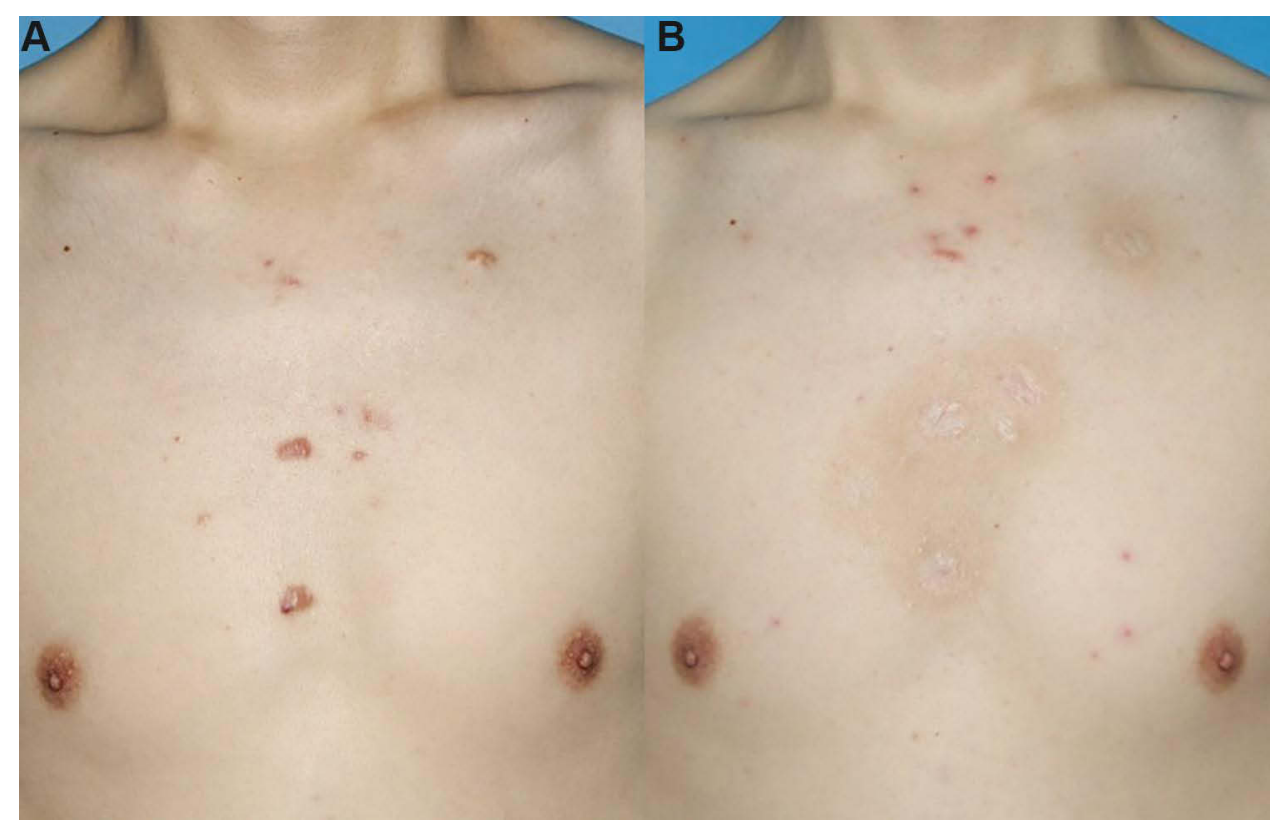

Figure 3 A patient with multiple lesions of keloids on his chest prior to treatment (A) and I year after PSR treatment with 2 radiation therapy thereafter (B). No recurrence was found.

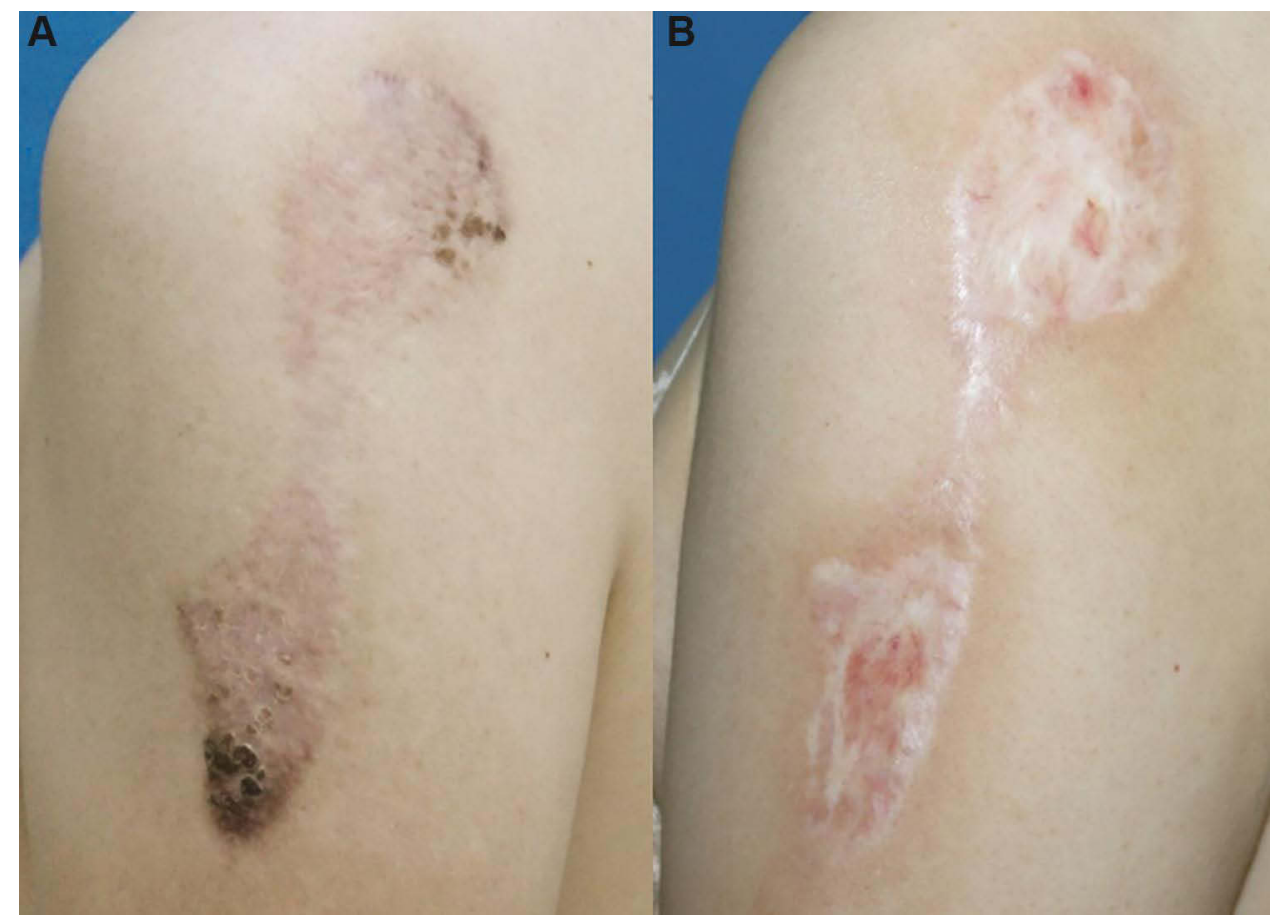

Figure 4 A patient with multiple lesions of keloids on her shoulder prior to treatment (A) and I year after PSR treatment with 2 radiation therapy thereafter (B). No recurrence was found.

$36.43 \pm 10.60$ to $20.00 \pm 6.62$ ( $\mathrm{p}$ value $<0.05$ ), with an improvement over $40 \%$. The mean score of keloids on chest and back also decreased from $41.08 \pm 10.29$ and $29.56 \pm 4.16$ to $24.15 \pm 7.82$ ( $\mathrm{p}$ value $<0.05$ ) and 18.19 $\pm 5.31 \quad$ ( $\mathrm{p}$ value $<0.05)$, respectively. However, improvement of keloids on shoulders and limbs was limited though still statistically significant. Table 3 demonstrates the six items that were evaluated by each patient. Comprehensive improvements were made on all items. Amelioration on pain and itchiness was over $50 \%$. 


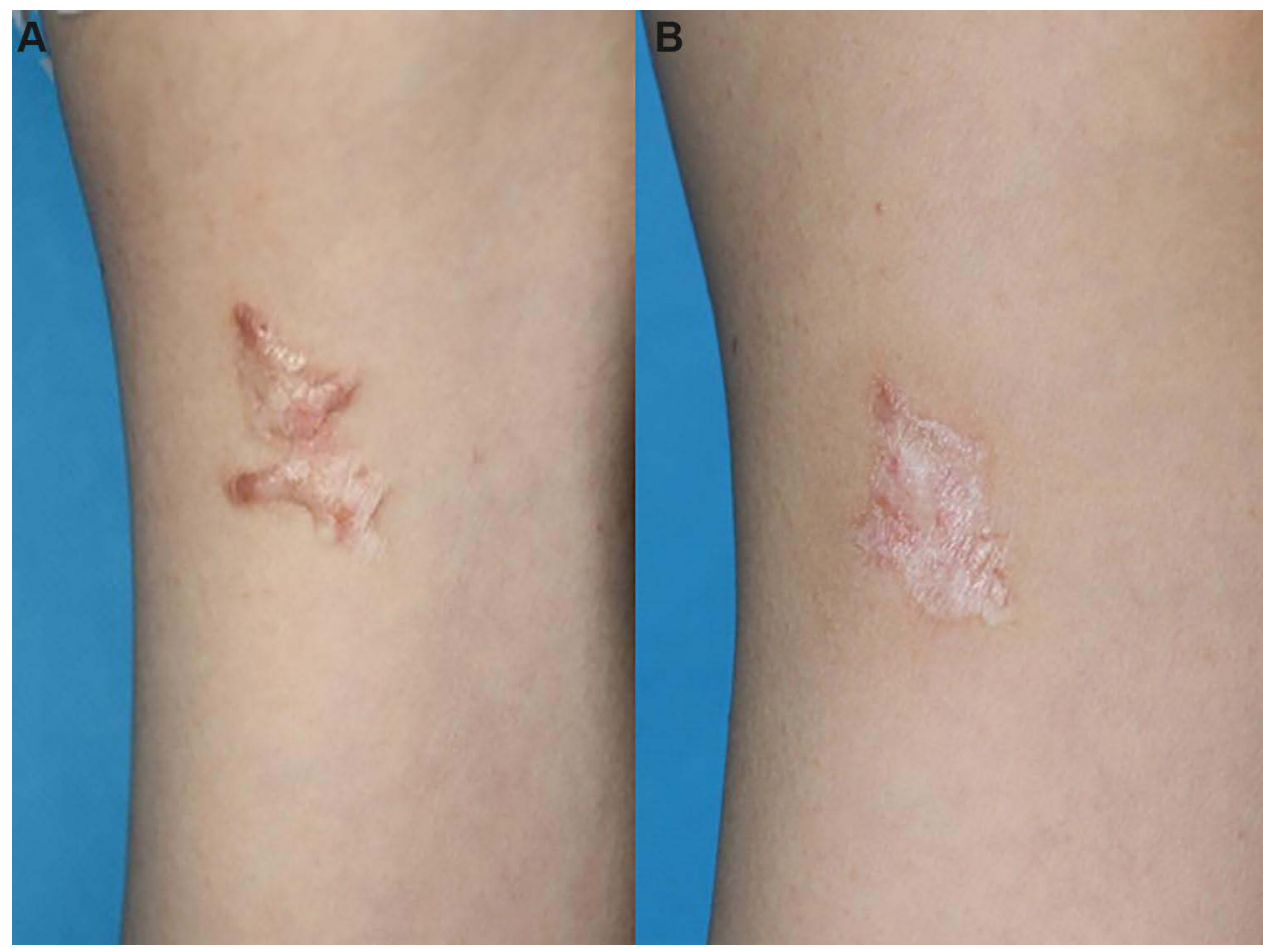

Figure 5 A patient with multiple lesions of keloids on her arm prior to treatment $(\mathbf{A})$ and I year after PSR treatment with 2 radiation therapy thereafter (B). No recurrence was found.

The results from the independent observer (Table 4) and the patients were consistent. The mean score of all 98 keloids

Table I Patient Demographics

\begin{tabular}{|l|l|}
\hline Number of Patients & I I \\
\hline Age & 1 \\
I0-19 & 56 \\
$20-29$ & 7 \\
$30-39$ & 4 \\
$40-49$ & 2 \\
$50-59$ & 1 \\
$60-69$ & \\
\hline Sex & 32 \\
Male & 39 \\
Female & 98 \\
\hline Number of lesions & \\
\hline Location & 23 \\
Face \& neck & 26 \\
Chest & 16 \\
Shoulders & 16 \\
Back & 17 \\
Limbs & $5.03 \pm 0.72$ \\
\hline Average lesion Size (cm) & $33.78 \pm 10.46$ \\
\hline Average re-epithelization duration (d) & $33 / 71$ \\
\hline Familial Inheritance Rate & \\
\hline
\end{tabular}

dropped from $37.59 \pm 8.17$ to $23.47 \pm 7.53$ ( $\mathrm{p}$ value $<0.05$ ). Keloids on face and neck, chest and back responded better to the treatment than those on shoulders and limbs. The observer score of six items is shown in Table 5. All items were significantly improved. Pigmentation (the extent of improvement in color) and relief (the extent of improvement in irregularities) were not improved remarkably as compared to the other four items, which corresponded with the results from the patient score. Figures 2Figures 3Figures 4Figures 5 showed keloids on different locations before and after treatment.

Adverse effects after radiation therapy are summarized in Table 6. Erythema and edema were common complications that occurred to almost all patients, but soon disappeared without special treatment. Local infection was reported by eight patients, and the type of infection was acne folliculitis. It was the main reason for which patients revisited our center in weeks after treatment. Late adverse effects included hyperpigmentation, hypopigmentation and radiation dermatitis. No case of carcinogenesis was reported. Complications of PSR were mild. Hyperpigmentation and hypopigmentation were complaints made by seven and five patients, respectively. During follow-up, 15 keloids (15.3\%) were observed or reported to relapse. Recurrent lesions were further treated with dye laser or steroid injection. 
Table 2 Total Patient-Reported Scores of Keloids on Different Body Parts Before and After Treatment

\begin{tabular}{|c|c|c|c|c|c|c|}
\hline & \multicolumn{2}{|c|}{ Before Treatment } & \multicolumn{2}{|c|}{ After Treatment } & \multirow[t]{2}{*}{$P$ value } & \multirow[t]{2}{*}{ Average Improvement } \\
\hline & Means \pm SD & Range & Means \pm SD & Range & & \\
\hline Face \& Neck $(n=23)$ & $36.43 \pm 10.60$ & $20-55$ & $20.00 \pm 6.62$ & $10-36$ & $<0.001$ & $40.2 \%$ \\
\hline Chest $(n=26)$ & $41.08 \pm 10.29$ & $21-60$ & $24.15 \pm 7.82$ & $12-39$ & $<0.001$ & $37.7 \%$ \\
\hline Shoulders $(n=16)$ & $29.19 \pm 6.33$ & $15-39$ & $21.63 \pm 7.25$ & $\mathrm{II}-34$ & 0.004 & $25.2 \%$ \\
\hline Back $(n=16)$ & $29.56 \pm 4.16$ & $21-35$ & $|8.19 \pm 5.3|$ & $12-33$ & $<0.001$ & $38.4 \%$ \\
\hline Limbs $(n=17)$ & $34.65 \pm 9.91$ & $21-53$ & $24.4 I \pm 5.88$ & $18-36$ & 0.001 & $27.5 \%$ \\
\hline Total $(n=98)$ & $35.05 \pm 9.94$ & $15-60$ & $21.84 \pm 7.04$ & $10-39$ & $<0.001$ & $34.6 \%$ \\
\hline
\end{tabular}

\section{Discussion}

Keloid has long bothered clinicians and patients as there is no standard therapy that gains universally approval. Single treatment, either surgical excision or laser therapy, has been repeatedly proven to result in high recurrence rate. $^{12}$ In the light of this, combination of keloid removal and adjuvant therapy has received much attention and increasingly more studies have shown its effectiveness with low recurrence rate. ${ }^{3-5}$ Adjuvant therapy includes a series of treatments that are administrated after surgical excision or laser therapy. Radiation therapy, steroid injection and silicone gel have all been reported to be effective adjuvant therapies. Park and Rah treated helical rim keloids with surgical excision plus silicone gel pressure therapy. ${ }^{13}$ The therapy protocol resulted in improvement on most items in the POSAS with recurrence-free rate of 95\%. Garg et al evaluated the effect of $\mathrm{CO}_{2}$ laser ablation followed by steroid injection. ${ }^{14}$ Their study illustrated that $\mathrm{CO}_{2}$ laser alone was not efficient enough while adding steroid injection as adjuvant therapy could significantly reduce recurrence rate. Hersant et al reported a pilot study using platelet-rich plasma injection as adjuvant therapy to surgical excision. ${ }^{15}$ Vancouver Scar Scale score was reduced by more than $50 \%$ after 2 -year follow-up though $29 \%$ of keloids relapsed. Considering that the keloids of

Table 3 Results of POSAS According to Patients

\begin{tabular}{|l|c|c|c|}
\hline & Before Treatment & After Treatment & P value \\
\cline { 2 - 3 } & Means \pm SD & Means \pm SD & \\
\hline Pain & $3.80 \pm 2.18$ & $1.68 \pm 0.91$ & $<0.01$ \\
Itch & $5.23 \pm 2.50$ & $2.17 \pm 1.34$ & \\
Color & $7.18 \pm 2.25$ & $5.48 \pm 2.37$ & \\
Stiffness & $7.28 \pm 2.28$ & $4.43 \pm 2.17$ & \\
Thickness & $7.22 \pm 2.56$ & $4.73 \pm 2.33$ & \\
Irregularity & $4.34 \pm 2.87$ & $3.34 \pm 1.90$ & \\
\hline
\end{tabular}

interest did not respond to conventional therapies, it was a satisfactory result.

Multiple treatments of PSR have been proven to be clinically effective for traumatic scars, mesh skin-grafted scars, and wrinkles at an interval of 3 weeks to 1 month. ${ }^{9,16}$ In this study, we reported single-dose PSR treatment combined with radiotherapy as an effective management for keloids. The endpoint of PSR therapy was when the lesions were almost as flat as the surrounding normal skin although red in color. More energy was applied for thicker lesions. An intralesional injection of the compound betamethasone was administered before PSR for thick lesions (thickness $>4 \mathrm{~mm}$ ) to avoid excessive plasma irradiation that could cause serious side effects and longer recovery time. However, for keloids less thick than $4 \mathrm{~mm}$, PSR was administered without the steroid injection. ${ }^{17}$ After PSR, a total of 18 Gy of radiation were administrated in two fractions, 24 hours posttreatment and again 1 week later. We regard adjuvant radiotherapy important in the prevention of recurrence. Numerous studies have shown surgery excision alone was followed by high recurrence rate, and that radiation therapy after keloid removal could significantly reduce recurrence rate to a desirable level. ${ }^{2,3}$ The mechanism of radiotherapeutic prevention remains unclear. One possible explanation is suggested to be the elimination of abnormally activated fibroblasts and stimulation of normal ones. ${ }^{18} \mathrm{Kal}$ et al recommended biologically effective dose for keloid prevention should be $30-40 \mathrm{~Gy}$, which could be achieved by either a single fraction of 13-15 Gy or 17-20 Gy in 2 fractions. ${ }^{19}$ Furthermore, radiotherapy was advocated to be administrated immediately after keloid removal or within 2 days. ${ }^{20}$ We strictly complied with these suggestions in this study.

Plasma combined with radiation therapy results in good clinical outcome, though improvement varies on different body parts. Keloids on face and neck, chest and 
Table 4 Total Observer-Reported Scores of Keloids on Different Body Parts Before and After Treatment

\begin{tabular}{|c|c|c|c|c|c|c|}
\hline & \multicolumn{2}{|c|}{ Before Treatment } & \multicolumn{2}{|c|}{ After Treatment } & \multirow[t]{2}{*}{ P value } & \multirow[t]{2}{*}{ Average Improvement } \\
\hline & Means \pm SD & Range & Means \pm SD & Range & & \\
\hline Face \& Neck $(n=23)$ & $42.52 \pm 6.47$ & $31-53$ & $21.87 \pm 6.72$ & $1 \mathrm{I}-40$ & $<0.001$ & $47.0 \%$ \\
\hline Chest $(n=26)$ & $42.62 \pm 6.44$ & $30-53$ & $24.42 \pm 8.28$ & $9-38$ & $<0.001$ & $42.3 \%$ \\
\hline Shoulders $(n=16)$ & $32.00 \pm 7.15$ & $24-46$ & $24.69 \pm 8.53$ & $15-43$ & 0.014 & $24.0 \%$ \\
\hline Back $(n=16)$ & $30.38 \pm 3.95$ & $23-36$ & $20.00 \pm 5.24$ & $13-32$ & $<0.001$ & $33.4 \%$ \\
\hline Limbs $(n=17)$ & $35.29 \pm 7.44$ & $19-49$ & $26.29 \pm 7.30$ & $15-38$ & 0.001 & $24.1 \%$ \\
\hline Overall $(n=98)$ & $37.59 \pm 8.17$ & $30-53$ & $23.47 \pm 7.53$ & $9-43$ & $<0.001$ & $35.8 \%$ \\
\hline
\end{tabular}

back were significantly improved after treatment according to both patients and observers. However, improvement of keloids on shoulders and limbs was limited. The frequent movement of these body parts results in high stretch tension that impedes collagen renewal and dermal remodeling. Though excessive proliferative fibrous tissue is removed, the rebuilding process of dermal architecture is relatively slower than that of lesions with less stretch tension.

In this study, complications are categorized by treatment area and duration. Complications after radiation therapy are considered adverse effects that occur within the radiation field beyond the lesion. Complications that limit to the lesion area are PSR-related. Acute adverse effects are defined as complications that disappeared within 4 weeks, while long-term adverse effects usually last longer than 1 month.

In terms of complications after radiation therapy, erythema and edema were reported by almost all patients in the first few days, but usually disappeared in 2 weeks without medication. In our follow-up, no patients resorted to medical treatment for long-lasting erythema or edema. Speranza et al confirmed that erythema was the most frequent acute side effect, but it had no association with patient satisfaction. ${ }^{21}$ Late complications reported by our

Table 5 Results of POSAS According to Observer

\begin{tabular}{|l|c|c|c|}
\hline & $\begin{array}{c}\text { Before } \\
\text { Treatment }\end{array}$ & $\begin{array}{c}\text { After } \\
\text { Treatment }\end{array}$ & \multirow{2}{*}{ P value } \\
\cline { 2 - 3 } & Means \pm SD & Means \pm SD & \\
\hline Vascularity & $6.95 \pm 1.36$ & $3.77 \pm 1.35$ & $<0.01$ \\
Pigmentation & $6.94 \pm 2.16$ & $5.01 \pm 2.30$ & \\
Thickness & $6.93 \pm 2.40$ & $4.26 \pm 2.31$ & \\
Relief & $4.42 \pm 2.71$ & $3.29 \pm 1.97$ & \\
Pliability & $6.97 \pm 2.23$ & $3.88 \pm 2.27$ & \\
Surface area & $5.38 \pm 2.04$ & $3.28 \pm 1.59$ & \\
\hline
\end{tabular}

patients include skin color change and chronic radiodermatitis. Permanent pigmentation and depigmentation are commonly reported to be a major late complication with incidence rate varying from $30 \%$ to $60 \%$ according to other studies. ${ }^{21,22}$ In this study, no case of necrosis or carcinogenesis was reported. Risk of radiation-induced tumor has been repeatedly proven to be very low. ${ }^{22}$ However, clinicians should always be cautious about the radiation energy in total when applying adjuvant radiotherapy. Sakamoto et al illustrated that relapse rate and adverse-effect were both dose-related. ${ }^{23}$ They recommended an optimal dose of $20 \mathrm{~Gy}$ in five fractions. We agreed that $18 \mathrm{~Gy}$ in 2 fractions is a nice balance between adverse effects and recurrence rate.

A few lesions developed hyperpigmentation or hypopigmentation limited to the area that received PSR treatment. These complications were considered PSR-related and had nothing to do with radiation therapy. Lesions with PSR-related complications were all thicker than $4 \mathrm{~mm}$ before treatment. However, it should be mentioned that not every thick lesion developed these complications. We speculate that this is because intralesional injection of steroid is insufficient for some thick lesions. Thick lesions

Table 6 Summary of Adverse Effects

\begin{tabular}{|l|l|}
\hline & \multicolumn{1}{|c|}{$\mathbf{n}(\%)$} \\
\hline $\begin{array}{l}\text { Acute adverse effects } \\
\text { Erythema } \\
\text { Edema } \\
\text { Infection }\end{array}$ & $\begin{array}{l}\text { Occurred to almost all patients, but } \\
\text { disappeared in 2 weeks } \\
8(8.2)\end{array}$ \\
\hline $\begin{array}{l}\text { Late adverse effects } \\
\text { Pigmentation } \\
\text { Hypopigmentation } \\
\text { Radiation dermatitis }\end{array}$ & $\begin{array}{l}3 \text { (3 (3.1.6) } \\
3(3.1)\end{array}$ \\
\hline Carcinogenesis & None \\
\hline
\end{tabular}


with insufficient steroid are not completely soften and thus require more energy to be flatten. The high energy level leads to adverse effects that do not develop at lower level of energy. In general, PSR should be considered a safe therapy with mild complications. An in vivo study showed that PSR could consistently achieve thermal injury into the papillary dermis resulting in collagen remodeling without permanent pigmentary or textural irregularities. ${ }^{24}$ Other studies also confirmed that PSR treatment caused less complications. According to Foster's study, no patient developed permanent hypopigmentation, a complication that is generally observed in $8-20 \%$ of $\mathrm{CO}_{2}$ resurfacing patients, although a very small proportion (4\%) of patients reported transient hyperpigmentation, which should be treated with hydroquinone creams or combination creams containing a mild topical corticosteroid, retinoid, and hydroquinone. ${ }^{25}$ Fitzpatrick et al reported that the thermal damage by PSR for any energy level was at most equivalent to medium fluence of the carbon dioxide laser and that the damage was confined within $15 \mu \mathrm{m}$ depth, in contrast to $33.4 \mu \mathrm{m}$ thermal damage created by high fluence of the carbon dioxide laser. ${ }^{26}$

In fact, not many risk factors other than ancestry, early age and skin injuries are known about keloid. But even less is known about factors that could possibly affect long-term curative effect. For example, sexuality, age, familial inheritance, and lesion size are all possible to influence clinical improvement. This study indicates keloids on different body parts may respond differently to the combination therapy. In the future, other factors that affect clinical outcome should be further studied with keloid location as a control factor.

This study has some limitations. Firstly, this is an observational study that evaluates the effectiveness and safety of PSR with adjuvant radiation therapy, while it does not compare PSR with other common treatment modalities. Randomized controlled studies are necessary for further evaluation of PSR. Secondly, the observation period of this study is relatively short to evaluate long-term curative effect, as previous studies reported that the control rate of keloid decreased 5 or 10 years or more after treatment. ${ }^{27,28}$ Thirdly, this study used a standardized scale for the evaluation of therapeutic effects. It has been mentioned that scale evaluation is subjected to a number of human factors and that objective assessment tools should be advocated. ${ }^{29}$ Application of objective assessment tools such as laser speckle contrast imaging and three-dimensional imaging could yield quantitative and more robust results. ${ }^{30,31}$

\section{Conclusion}

Plasma Skin Regeneration combined with adjuvant radiation therapy should be regarded as a safe, low-risk, effective treatment for keloids. Steroid could be administrated for thick lesions before PSR to avoid excessive thermal effect that increases the rate of side effects.

\section{Disclosure}

The authors declare no conflicts of interest for this work.

\section{References}

1. Ogawa R. Keloid and hypertrophic scars are the result of chronic inflammation in the reticular dermis. Int J Mol Sci. 2017;18(3):606.

2. Al-Attar A, Mess S, Thomassen JM, Kauffman CL, Davison SP. Keloid pathogenesis and treatment. Plast Reconstr Surg. 2006;117 (1):286-300. doi:10.1097/01.prs.0000195073.73580.46

3. Jones ME, Ganzer CA, Bennett D, Finizio A. Surgical excision of keloids followed by in-office superficial radiation therapy: prospective study examining clinical outcomes. Plast Reconstr Surg Glob Open. 2019;7(5):e2212. doi:10.1097/GOX.0000000000002212

4. Chua SC, Gidaszewski B, Khajehei M. Efficacy of surgical excision and sub-dermal injection of triamcinolone acetonide for treatment of keloid scars after caesarean section: a single blind randomised controlled trial protocol. Trials. 2019;20(1):363. doi:10.1186/s13063019-3465-6

5. Stromps JP, Dunda S, Eppstein RJ, Babic D, Har-Shai Y, Pallua N. Intralesional cryosurgery combined with topical silicone gel sheeting for the treatment of refractory keloids. Dermatol Surg. 2014;40 (9):996-1003. doi:10.1097/01.DSS.0000452627.91586.cc

6. Koike S, Akaishi S, Nagashima Y, Dohi T, Hyakusoku H, Ogawa R. Nd:YAG laser treatment for keloids and hypertrophic scars: an analysis of 102 cases. Plast Reconstr Surg Glob Open. 2014;2(12):e272. doi:10.1097/GOX.0000000000000231

7. Henderson DL, Cromwell TA, Mes LG. Argon and carbon dioxide laser treatment of hypertrophic and keloid scars. Lasers Surg Med. 1984;3(4):271-277. doi:10.1002/lsm.1900030402

8. Li K, Nicoli F, Xi WJ, et al. The $1470 \mathrm{~nm}$ diode laser with an intralesional fiber device: a proposed solution for the treatment of inflamed and infected keloids. Burns Trauma. 2019;7:5. doi:10.1186/ s41038-019-0143-6

9. Kono T, Groff WF, Sakurai H, Yamaki T, Soejima K, Nozaki M. Treatment of traumatic scars using plasma skin regeneration (PSR) system. Lasers Surg Med. 2009;41(2):128-130. doi:10.1002/ $1 \mathrm{sm} .20723$

10. Berman B, Maderal A, Raphael B. Keloids and hypertrophic scars: pathophysiology, classification, and treatment. Dermatol Surg. 2017;43(Suppl 1):S3-S18. doi:10.1097/DSS.0000000000000819

11. Draaijers LJ, Tempelman FRH, Botman YAM, et al. The patient and observer scar assessment scale: a reliable and feasible tool for scar evaluation. Plast Reconstr Surg. 2004;113(7):1960-1965. doi:10.1097/01.PRS.0000122207.28773.56

12. Arno AI, Gauglitz GG, Barret JP, Jeschke MG. Up-to-date approach to manage keloids and hypertrophic scars: a useful guide. Burns. 2014;40(7):1255-1266. doi:10.1016/j.burns.2014.02.011

13. Park TH, Rah DK. Successful eradication of helical rim keloids with surgical excision followed by pressure therapy using a combination of magnets and silicone gel sheeting. Int Wound J. 2017;14 (2):302-306. doi:10.1111/iwj.12547

14. Garg GA, Sao PP, Khopkar US. Effect of carbon dioxide laser ablation followed by intralesional steroids on keloids. J Cutan Aesthet Surg. 2011;4(1):2-6. doi:10.4103/0974-2077.79176 
15. Hersant B, SidAhmed-Mezi M, Picard F, et al. Efficacy of autologous platelet concentrates as adjuvant therapy to surgical excision in the treatment of keloid scars refractory to conventional treatments: a Pilot Prospective Study. Ann Plast Surg. 2018;81(2):170-175. doi:10.1097/SAP.0000000000001448

16. Theppornpitak N, Udompataikul M, Chalermchai T, Ophaswongse S, Limtanyakul P. Nitrogen plasma skin regeneration for the treatment of mild-to-moderate periorbital wrinkles: a prospective, randomized, controlled evaluator-blinded trial. J Cosmet Dermatol. 2019;18 (1):163-168. doi:10.1111/jocd.12767

17. Park KY, Lee Y, Hong JY, Chung WS, Kim MN, Kim BJ. Vibration anesthesia for pain reduction during intralesional steroid injection for keloid treatment. Dermatol Surg. 2017;43(5):724-727. doi:10.1097/ DSS.0000000000001040

18. Stadelmann WK, Digenis AG, Tobin GR. Physiology and healing dynamics of chronic cutaneous wounds. Am J Surg. 1998;176:28S38S. doi:10.1016/S0002-9610(98)00183-4

19. Kal HB, Veen RE, Jurgenliemk-Schulz IM. Dose-effect relationships for recurrence of keloid and pterygium after surgery and radiotherapy. Int J Radiat Oncol Biol Phys. 2009;74(1):245-251. doi:10.1016/j.ijrobp.2008.12.066

20. Bischof M, Krempien R, Debus J, Treiber M. Postoperative electron beam radiotherapy for keloids: objective findings and patient satisfaction in self-assessment. Int $J$ Dermatol. 2007;46:971-975. doi:10.1111/j.1365-4632.2007.03326.x

21. Speranza G, Sultanem K, Muanza T. Descriptive study of patients receiving excision and radiotherapy for keloids. Int $J$ Radiat Oncol Biol Phys. 2008;71(5):1465-1469. doi:10.1016/j.ijrobp.2007.12.015

22. Ogawa R, Yoshitatsu S, Yoshida K, Miyashita T. Is radiation therapy for keloids acceptable? The risk of radiation-induced carcinogenesis. Plast Reconstr Surg. 2009;124(4):1196-1201. doi:10.1097/ PRS.0b013e3181b5a3ae

23. Sakamoto T, Oya N, Shibuya K, Nagata Y, Hiraoka M. Doseresponse relationship and dose optimization in radiotherapy of postoperative keloids. Radiother Oncol. 2009;91(2):271-276. doi:10.1016/j.radonc.2008.12.018
24. Tremblay JF, Moy RL. Treatment of post-auricular skin using a novel plasma resurfacing system: an in vivo clinical and histologic study. Lasers Surg Med. 2004;34:25.

25. Foster KW, Moy RL, Fincher EF. Advances in plasma skin regeneration. J Cosmet Dermatol. 2008;7:169-179. doi:10.1111/ j.1473-2165.2008.00385.x

26. Fitzpatrick R, Bernstein E, Iyer S, Brown D, Andrews P, Penny K. A histopathologic evaluation of the Plasma Skin Regeneration System (PSR) versus a standard carbon dioxide resurfacing laser in an animal model. Lasers Surg Med. 2008;40(2):93-99. doi:10.1002/ lsm. 20547

27. Shen J, Lian X, Sun Y, et al. Hypofractionated electron-beam radiation therapy for keloids: retrospective study of 568 cases with 834 lesions. J Radiat Res. 2015;56(5):811-817. doi:10.1093/jrr/rrv031

28. Maemoto $H$, Iraha $\mathrm{S}$, Arashiro $\mathrm{K}$, Ishigami $\mathrm{K}$, Ganaha $\mathrm{F}$, Murayama S. Risk factors of recurrence after postoperative electron beam radiation therapy for keloid: comparison of long-term local control rate. Rep Pract Oncol Radiother. 2020;25(4):606-611. doi:10.1016/j.rpor.2020.05.001

29. Chong Y, Long X, Ho YS. Scientific landscape and trend analysis of keloid research: a 30-year bibliometric review. Ann Transl Med. 2021;9(11):945. doi:10.21037/atm-21-508

30. Xu C, Ting W, Teng Y, Long X, Wang X. Laser speckle contrast imaging for the objective assessment of blood perfusion in keloids treated with dual-wavelength laser therapy. Dermatol Surg. 2021;47 (4):e117-e121. doi:10.1097/DSS.0000000000002836

31. Ruccia F, Zoccali G, Cooper L, Rosten C, Nduka C. A three-dimensional scar assessment tool for keloid scars: volume, erythema and melanin quantified. Skin Res Technol. 2021; Epub. doi:10.1111/srt. 13050

\section{Publish your work in this journal}

Clinical, Cosmetic and Investigational Dermatology is an international, peer-reviewed, open access, online journal that focuses on the latest clinical and experimental research in all aspects of skin disease and cosmetic interventions. This journal is indexed on CAS.
The manuscript management system is completely online and includes a very quick and fair peer-review system, which is all easy to use. Visit http://www.dovepress.com/testimonials.php to read real quotes from published authors. 